\title{
Flip Side of the Coin: Negative Socio-Economic Implications of ICT
}

\author{
Sergey Samoilenko (Corresponding author) \\ Department of CIS/CS, Averett University \\ 420 West Main Street, Danville, Virginia 24541, United States
}

Tel: 1-434-791-5729Ｅ-mail: ssamoilenko@averett.edu

Received: April 7, 2020 Accepted: April 25, 2020 Published: May 6, 2020

doi:10.5296/ber.v10i2.16973 URL: https://doi.org/10.5296/ber.v10i2.16973

\begin{abstract}
While positive impacts of ICT have been noted and subjected to numerous academic inquiries, the negative implications are often swept under the proverbial rug and not given much attention. The subject of the negative impacts of ICT, however, is worth considering, for such impacts are observable in a variety of economies of the world and must be dealt with. An intuitive taxonomy of problems could be created based on four dimensions: social vs. economic implications and intra-economy vs. inter-economy impacts. A set of research suggestions could offer assistance in investigating negative impacts of ICT in a rigorous and relevant to the local context manner.
\end{abstract}

Keywords: Information and communication technology, Social impact, Economic impact, Investments in ICT, Globalization, Elimination and substitution

\section{Introduction}

Socio-economic impacts of Information and Communication Technologies (ICT) have been extensively researched in diverse contexts, within different time frames, and by various methods of inquiry. It is fair to say there is a general consensus that investments in ICT result in "good things" of various kinds. After reading findings of published research, one feels that investing in ICT is similar to buying a night-time cough medicine to help your cold feel better next morning. You pay the price (for ICT does not come free), you take the medicine (ICT needs to be integrated and implemented), and you wait (there is a time lag). And it usually works as advertised- you do feel better and all seems to be well. The medicine does not work perfectly, but it never completely fails. So, overall, this medicine, as well as ICT, is a "good thing." However, a medicine always comes with warnings of side effects- there is a disclosure mentioning an additional price to pay for getting a "good thing" going. 
Unlike medicine, side effects of "good things" brought about by ICT are almost impolite to mention- for the technological progress and productivity growth usually come first and rank high on any economy's list of priorities. And they should come first, for it is better to make money, generate wealth, and then re-distribute them if needed, than to be ready to re-distribute, but having nothing to give. But there is a price to pay for economic development- side effects are there whether we want it or not.

Technology and progress are like a big ship taking off the pier and heading full speed to the sea- moving economies forward, but leaving some small boats greatly disturbed in its wake. We should not try to stop, or slow down, this big ship, but we should be aware of what it leaves in its wake, so we are prepared for little boats to be in trouble.

This is, really, a matter of comparing and contrasting "big deals." Increasing efficiency and effectiveness of a business process, or a governmental service, or an Internet access is a big deal, indeed. We can trace the impact to growth in productivity, and then, in turn, to the macroeconomic outcome- growth in GDP. But there are other "bid deals."

Big deal if a local mom-and-pop store went out of business- are you not happy, instead, to use a self-checkout station in a local supermarket? Well, a cashier that knew your name is gone, but the process is much quicker now, no cashier is needed and prices are lower. Much lower than in that mom-and-pop store, now out of business, where locals used to meet.

Some of the negatives are situation-specific and unique to a given setting offering researchers anecdotal evidence. Other negatives are philosophically inevitable- they will be present regardless of the context. If you are in business of designing bombs, then you should aim for making the most efficient and effective once- just business, nothing personal. However, it is good to be aware of a collateral damage of a bomb maker' success.

Our objective in this paper is to bring attention of our colleagues to some of the "negative inevitables" of positive impacts of ICT (Bosamia, 2013, Tarafdar et al., 2013, Tarafdar et al., 2015). Along the way we will try to suggest a way of categorizing the negatives. Finally, we will attempt to propose possible routes of investigating them. A full disclosure to our readersit is not our purpose to rain on a parade of positive impacts of ICT, but it is our goal to suggest to our colleagues that ICT-driven initiatives aiming for "good things" should come with a warning label mentioning side effects.

\section{Socio-Economic Impact of ICT}

The purpose of this part of the paper is to analyze some of the negative (sometimes intended and sometimes unintended) implications of implementation and usage of ICT in a variety of contexts. This will be followed by a suggestion of possible research-relevant considerations.

\subsection{Tools, Machines, and ICT}

Before ICT was a "good thing", there were machines, and before machines there were tools"good things", all. It is important to mention them because they are inextricably linked together. 
An introduction of tools, machines, and ICT has a shared objective- to make an execution of work more effective and efficient, which pursued according to the same strategy, that of elimination and substitution. But while tools, machines, and ICT share a common objective and a common strategy, they implement them by following different routes. Let us spend a minute clarifying terminology used in this paper.

Physical work is an act of applying energy to matter with the purpose of transforming its properties. Physical work has its counterpart in digital domain. Digital work is as an act of collecting, manipulating, storing, or disseminating of data- an act of applying energy to data with the purpose of changing its properties- location, format, encoding, encryption, etc. A work element is a part of work, a task that could be performed by a single worker. A sharpening of a knife, or an entry of a record into a database are examples of work elements.

A tool is an object, natural or manmade, allowing for a more efficient and effective performance of a function within a work element. A knife sharpener and a document scanner are examples of tools.

A machine is a system incorporating a tool(s) allowing for a more efficient and effective performance of work. A knife sharpening machine is an example of a machine in the mechanical domain. A digital graphing calculator is an example of a digital machine.

An Information Technology (IT) is an electronic symbol generating and processing system comprised of software and hardware that allows for assessing, via generating information, the working order, or a state, of a machine. IT-enabled sharpening machine allows for monitoring a number of surfaces sharpened, a wearing out of the sharpening tool, and the time-to-service left- once it is up the warning message appears. A laptop is an example of IT that controls the state of multiple virtual machines- applications.

Information and Communication Technology (ICT) is an IT-based system that creates new, or optimizes existing, information channels which allow for controlling a set of virtual or IT-controlled machines involved in a complex workflow (work processes). An automated order fulfillment center and a cloud-based on-line payment system are examples of ICT.

\subsection{Routes of Elimination and Substitution}

Let us take a look at various ways by which tools, machines, and ICT bring about "good things." A tool allows for increasing efficiency and effectiveness of performing a work element via eliminating a direct involvement of a human body part(s) in performing work by means of substituting it with an object. Hitting your enemy in the head using a hammer is more efficient and effective than using a fist. Digitally recording a song is more effective and efficient than doing so in analog way, whether recording it on a vinyl disk or via transcribing its text and notes.

A machine allows for increasing efficiency and effectiveness of work via mechanization or automation- by eliminating human involvement in repetitive work by means of substituting humans equipped with tools. An Information Technology (IT) allows for increasing efficiency and effectiveness of work via substituting humans controlling the machines. An automated 
production line' control system or a self-checkout counter at the grocery store both eliminate significant human involvement.

An ICT takes it a step further and achieves the objective via substituting human decision-making process geared towards an optimization of a workflow. Just-in-time (JIT) manufacturing system, or Apple' iTunes store are examples here. In both cases human involvement is minimized.

An Artificial Intelligence (AI)-enabled ICT aims to replace human decision making within a novel context (e.g., changed business environment) of a workflow. Collaterally, AI is a tool that attempts to manipulate human decision-making processes.

The impact of elimination and substitution via tools, machines, and ICT is compound because the elements in the elimination and substitution chain are interdependent. Better tools allow for integrating them in more complex machines that are controlled by the increasingly sophisticated software component of IT, and the complex machines could be interconnected via ICT (especially AI-enabled ICT) to comprise a complex workflow. Consequently, if entity A invests in a more sophisticated ICT than entity B, then, ceteris paribus, entity A should be able achieve a greater level of effectiveness and efficiency of work via elimination and substitution alone.

However, there is inevitable impedance mismatch within the elimination and substitution chain if the chain incorporates analog physical work and digital symbolic processing and control. This means that even the most sophisticated warehouse or distribution center (e.g., Amazon' ones) will not be able to eliminate as many people as would be possible otherwise. The maximum effect the chain achieves in the case of moving all the work into a digital domain (e.g., Instagram replaced 100K Kodak' employees). For example, a branch of a bank with an on-ground presence will have to have some on-ground employees left as long as they deal with physical money. If, however, the bank or a financial institution moves its operations completely into a digital domain, then the success of the substitution and elimination chain could be much greater.

In any case, digital or analog, any implementation of ICT will result in inevitable elimination and substitution, somewhere along the chain, of human involvement.

Furthermore, this impact remains regardless the type of workflow- whether the work is accomplished for the benefits of shareholders (e.g., any implementation of Enterprise Systems), or if it is done for personal, leisurely purposes (e.g., subscribing to a new service or downloading a new app to your smartphone). At this point we are in a good position to state Negative Inevitable \#1:

\section{Investments in ICT will result in a substitution and elimination of human involvement}

\subsection{Conditions of Elimination and Substitution}

In principle, there are two conditions when technology (e.g., tools, machines, ICT) will not be used to substitute and eliminate human involvement. First, when there is no available technology to do so and, second, when technology is available, but it is cheaper to use 
humans.

There are some important implications resulting from these conditions.

In the first case it is worth considering a situation under which "available technology" is equivalent to "affordable technology", for both cases will result in the same outcome- there will be no substitution. In the instance of ICT this is relevant, for a competitive advantage nowadays comes not from an ability to do work (which is a given), but from an ability to coordinate complex workflows. And it is in the domain of coordination of work that ICT shines. Thus, by improving the chain "resource->tools->machines->IT-enabled machines" an economy that cannot afford ICT may only go so far. This means that an economy that cannot afford needed ICT will not be able to make more money to afford it, but will have to wait until prices of such ICT are reduced sufficiently to be affordable. Basically, the economy will find itself dragging further and further behind those who can afford it now.

In the second case, if we ask ourselves a question Where is it cheaper to use humans than technology in 21 st century? We can come up with a surprisingly long list of places. In all of those contexts' investments in ICT, however important, should not be considered an overriding priority. Instead, the priority should be in transitioning from human labor to machines, and then to IT-enabled machines.

But, for many economies that cannot afford ICT there are external sources that could help with the funding. So, what would be a negative consequence of getting a technology that an economy cannot really afford or could do without because human labor is cheaper? To answer this question, we need to consider the complete chain "Resources->Tools->Machines->IT-enabled Machines->ICT" to see that the introduction of ICT will expose shortcomings and conflicts within the next link below- "IT-enabled machines." Basically, an introduction of advanced (for a given context) ICT will result in a situation of "OK, now we have the technology to connect IT-controlled machines, but how do we get the machines up to speed now?" At this point we can state Negative Inevitable \#2:

Introduction of advanced-for-the-context ICT will magnify the existing, and identify new, deficiencies within the state of IT-enabled machines.

\subsection{Pragmatics and Ethics of Implementation}

A different set of potential problems emerges if we consider the inevitable gap between an output of the implementation of ICT and the outcome of it. Investments in ICT are allocated primarily towards impacting the current infrastructure of the context and, naturally, the intended result is delivered via the implemented ICT, which is not an end to itself, but a mean to a greater end- a positive socio-economic impact. Overall, the following chain of links is traceable: "Investments in ICT $\rightarrow$ Implementation of ICT $\rightarrow$ Impact of Implemented ICT", which is, for all intents and purposes, a chain "Investments in ICT $\rightarrow$ Output $\rightarrow$ Outcome."

Thus, the actual resultant ICT is the output of the process of implementation of investments in ICT. It is of no use to have investments in ICT available as an end game, for it is just a line on a balance sheet that makes an account look good, but doing not much beyond that. 
Consequently, investments must be allocated and implemented to produce an impact, and the most common way to introduce new technologies is via using ISD methodologies.

The overwhelming majority of methodologies used in the process are functionalist - based on mechanistic approach and driven by pragmatic considerations. The quality of the output, therefore, is judged based on the appropriate to functionalism criteria, which, in the case of the chain "Resource $\rightarrow$ Tool $\rightarrow$ Machine $\rightarrow$ IT-controlled Machine $\rightarrow I C T$ ", translates into increased effectiveness and efficiency of the chain.

A greater impact of ICT, however, resides not in the output of the process of implementation, but in the outcome of the process within a larger system. This forces us to move out of a narrow technological domain into a more complex social domain, where the assessment of the impact of ICT is no longer driven by pragmatics, but, instead, by ethics.

Resultantly, it is only expected to anticipate a presence of incongruence between the output of ICT and the outcome of it, for pragmatics and ethics are based on different principles and assumptions. Now we are well-equipped to state Negative Inevitable \#3:

An assessment of the impact of ICT will require reconciliation of differences between the pragmatics of the implementation of ICT and the ethics of the expected results of the implementation.

Let us spend some time considering the aspects of a social domain that could be impacted, positively and negatively, by ICT.

\subsection{Dimensions of Social Impact of ICT}

Introduction of ICT results in changes in the host's social environment- even if the implementation itself is purely technical, impacts of the implementation spread beyond the boundaries of purely technological domain. Regardless of the context, no society is homogeneous, and we need to consider what sort of dimensions are responsible for heterogeneity, for every one of them will be impacted by ICT.

We will consider only the most obvious ones- economic, cultural, political, and religious. At this point we are not going to be concerned with the "interaction effects" such as "wealthy liberal", "poor conservative", and so on. An uber dimension that is responsible for differentiating a society is economics. In the case of introducing a new and improved ICT the financially better off groups of society will disproportionally benefit from the change. After all, it is the members of any society that have more advanced IT that benefit from ICT the most. Consider having a new high-speed highway- the introduction of a new road is a good thing for any driver, but the drivers having better cars will benefit the most, while the owners of the old ones may struggle to adjust their vehicles to new conditions (e.g., higher speed limit).

At this point Negative Inevitable \#4 seems to be in order:

Economically disadvantaged groups of a society will be negatively impacted by the introduction of new ICTs due to the pressures of the compliance with the new technology and 
the limited use of new capabilities due to restrictions associated with the old technology.

However, pressures on a technological front are only a beginning of the impact of new ICTlet us consider other ones as well.

\subsection{Platform, Message, and Target}

It is fair to say that almost any coherent, organized, and recognizable/identifiable subgroup in a society has its own platform and its own message, as well as an intended target of the message. We define a platform as a collection of the available information channels allowing for transmitting of the group's message. A message is a statement containing a set of propositions reflecting the political, cultural, or religious values (or a combination of them) that the group wants to impart to a target. A target is an intended audience of the message, which could be another subgroup or a society in general. Introduction of new ICT brings some interesting consequences impacting platforms, messages, and targets that are worth considering.

A new ICT will allow for creating new and optimizing existing information channels. Thus, in the case of an affluent subgroup, its platform will become wider due to quantitative and qualitative changes the new ICT will bring. Quantitative changes are associated with the platform gaining a greater number of information channels of the same type, and qualitative changes are associated with gaining a greater variety of the types of information channels (e.g., text, audio, video, digital art, etc.).

The platform will also become taller via allowing for reaching a wider audience- a bigger target group. So, a new ICT is a "good thing" for a well-off group. In the case of an economically disadvantaged subgroup, however, the platform will become relatively narrower, because it will require a newer technology to utilize new ICT to the full extent. Also, the platform will become relatively lower, because some of the previously accessible audiences will transition to using new technology that is not available to the poorer subgroup.

It is possible, of course, that the new ICT will not result in reduction of the width and height of the platform of an economically disadvantaged group. However, because the economically advantaged group will take an opportunity of the new ICT, this will make their platform wider and taller than it previously was. Hence our use of the term relatively- even if the platform of the disadvantaged group stays the same, its width and height deteriorates relative to the competition. Consequently, Negative Inevitable \#5 is as follows:

Introduction of new ICT will result in a relative deterioration of the social platform of the economically disadvantaged subgroups of a society.

Some interesting things happen to messages. While the substance, the content of the message may stay the same (it does not have to, but let us assume the simplest scenario), the two characteristics of a message will be impacted greatly. These characteristics are format and intensity. New ICTs offers new types of information channels, which allow for a delivery of a message in a greater variety of formats (e.g., text, audio, video, etc.) and with a greater frequency. Increasing a variety of formats and a frequency of delivery neither come free, nor 
cheaply. Hence, an introduction of new ICT will result in a relative decrease of intensity and a relative decrease of attractiveness of the format of the message in the case of economically disadvantaged subgroups. It is important to note that we are not talking about a content - the substance of the message, but only about its' packaging and a frequency of delivery.

Resultantly, we put forward Negative Inevitable \# 6 as follows:

For economically disadvantaged subgroups an introduction of new ICT will bring a relative decrease in (1) frequency of delivery and (2) attractiveness of the format of their message.

Introduction of a new ICT also impacts targets. It is safe to say that the majority of active subgroups in any society aim to reach outside its own constituency to promote their set of values. Let us consider a simple scenario where a subgroup has its loyal following and constituency that will not be impacted by the introduction of new ICT. The outside targets, however, will be impacted by the new ICT - the impact is based on what we call continuously rising expectation regarding the wrap and drop. It is only to be expected that people expect messages to be nicely wrapped-delivered to them in the best possible/available format (e.g., high-production video vs. text), and continuously dropped-delivered to them regularly and often. Targets, whether they want it or not, will become fickler as they are offered more choices which raise their expectations.

It is only reasonable to suggest, then, that format wars and delivery battles will take place, and will play out with fairly predictable results. Economically better off subgroups will win format wars because they have a financial edge in producing, or paying to produce, messages in a better wrapper- in a higher quality format. Also, it is only to be expected that more affluent subgroups will win delivery battles because they will have more resources for delivering messages more frequently and on-demand- a fast food delivery model will prevail in digital domain.

Simply put, a Darwinian' message selection by a target plays out, where fast and pretty survives, and slow and substantive dies.

Now we can state Negative Inevitable \# 7, as follows:

For economically disadvantaged subgroups an introduction of new ICTs will make reaching the target of their message relatively harder.

Let us now consider some political and cultural implications of ICT, where two negatives come to mind. First, an introduction of an advanced ICT will result in a further consolidation of political powers around the affluent centers. The reason is simple- the fundamental architecture of the Internet is based on a client-server model, and the centers of control and influence are usually formed around the servers. Consequently, if the resources of an economy are in the hands of a government (or, government- controlling entities), then mechanisms of political suppression will become more effective and efficient, specifically in the context of non-democratic societies. Simply put, bigger, better, faster servers will force re-centralization of decentralized model of the Internet-based computation, with all the political impacts it may bring. We suggest a Negative Inevitable \# 8, as follows: 
In the societies of a globalized world introduction of new ICT will strengthen the existing political status quo.

A second implication is associated with the purpose of the culture of a society, which is to provide a shared, stable and consistent world-view to its members. An introduction of such change agent as advanced ICT may not result in a significant cultural impact in the context of the Western world, but in a context of societies that are based on different cultural premises it may. We should not forget that ICT is a messenger of such powerful mechanistic ideas as positivism, determinism, and individualism, and it requires a compliance with them to be utilized effectively and efficiently. It is not entirely unlike the democratic ideas of the West, which were successfully adopted by many post-Soviet countries in Europe, but did not root well in Arab world and Africa due to fundamental cultural differences. Simply put, ICT requires an appropriate cultural soil to take off, for, otherwise, cultural clashes are inevitable. We offer a Negative Inevitable \# 9, as follows:

An expected corollary to the outcome of the implementation of the ICT in the non-Western context of the globalized world is a struggle to reconcile the values of the Western culture with the local one.

Additionally, there are also ICT-driven changes that impact inter-economy situation. We consider them next.

\subsection{Competing with Others: Additional Implications}

An introduction of the new ICT will also have an inter-economy impact, for changes brought about by ICT rarely can be contained within a single economy. Let us consider two simple scenarios to illustrate the implications.

The first scenario refers to the situation when Economy A wants to gain a competitive edge over Economy B via the introduction of the new ICT. We consider such situation playing out via two intuitive cases.

The first case is when both economies have well-integrated and developed chains "Resources $\rightarrow$ Tools- $\rightarrow$ Machines $\rightarrow$ IT-enabled Machines" and investing in new ICT does make a competitive sense for Economy A. However, the resultant competitive edge will be short-lived, for all it takes for Economy B to catch up is to invest in its own new ICT as well. Thus, once Economy B also gets its new ICT, the obvious next step for Economy A is to make the complete chain "Resources $\rightarrow$ Tools $\rightarrow$ Machines $\rightarrow$ IT-enabled Machines $\rightarrow$ ICT" leaner relative to Economy B. And this "leaning out" of a workflow chain will impact the involved labor force- elimination and substitution of the workforce will take place. However, the impact on the labor force will be greater because it will be driven by two factors working in synergy. The first factor is new ICT and its impact on a workflow chain, where "as-is" state with X employees will be replaced by "to-be" state with X-n employees.

The second, compounding factor, is a competition with Economy B. Given the fact that Economy B will go through its own "as-is" to "to-be" transformation resulting in Y-m employees, Economy A will attempt to gain a competitive advantage via the second round of 
elimination and substitution aiming at prevailing over Economy $\mathrm{B}$ via assuring that the equation $(\mathrm{X}-\mathrm{n})<(\mathrm{Y}-\mathrm{m})$ remains valid.

The second scenario refers to the situation when Economy A, in the absence of the well-integrated and developed chain "Resources $\rightarrow$ Tools $\rightarrow$ Machines $\rightarrow$ IT-enabled Machines", invests in new ICT aiming to attract outside investments (e.g., FDI) and, resultantly, gain an edge over Economy $\mathrm{B}$ via this route. However, it is only reasonable to assume that such plan will fail- two reasons come to mind. First, no external funds may come about if the outside investments will aim to take advantage of well-developed and integrated chain "Resources $\rightarrow$ Tools $\rightarrow$ Machines $\rightarrow$ IT-enabled Machines $\rightarrow$ ICT." Second, external funds could be allocated under condition of improving the "Resources $\rightarrow$ Tools $\rightarrow$ Machines $\rightarrow$ IT-enabled Machines $\rightarrow I C T$ " chain. Because investments more often than not are allocated for the purpose of making profit, external entities will have a goal of using Economy A to compete against Economy $\mathrm{X}$. This results in a familiar scenario of elimination and substitution resulting, first, in X-n as a result of new ICT, and second, (X-n)-k as a result of the pressure from external investors competing against Economy $\mathrm{X}$. At this point we put forward Negative Inevitable \# 8, as follows:

An introduction of new ICT as a tool of inter-economy competition will result in an increased level of elimination and substitution of the workforce.

\subsection{Competing with Others: Social Implications}

Inter-economy competition would also bring about some interesting political, cultural, and religious implications. While the extent of the impact along those dimensions is context-specific and indicative of local inflections, the general tendency can be traced. ICT-based competition will result in economic stratification of a society based on three consequences of the implementation of ICT. First, there will be displaced employees whose jobs were eliminated and substituted by IT. This is important to note: this is not a scenario of "you can get a raise or you can get a cut", but, rather, it is a scenario of "sorry, there is nothing for you." Displaced employees will come from all three organizational levelsoperational, tactical, and strategic.

Second, there will be a drive to eliminate middle managers- some of them will be eliminated, others will become a part of a strategic level, and yet others will descend to operational level. Appropriate levels of compensation (e.g., increased, decreased, welfare, etc.) will determine the strata of the destination.

Finally, there will be a greater disconnect between operational level of a firm, and its strategic level. The reason is simple- the interface, the middle managers, is gone.

This stratification of the society based on economics results in strengthening of the cohesiveness of the political, cultural, and religious subgroups. A general need for an affiliation will drive people towards joining or becoming more active in, what is perceived as, "stable, consistent, and reliable" social group. That, in turn, will lead to "us vs. them" attitude of the members of subgroups. Interestingly, this attitude will have two directions- internal and external. The internal direction will be pointed against the subgroups of the homeland 
economy that are perceived to be responsible for negative changes that took place and impacted the local labor force. The external direction will have its aim on the members of "other" economy (or economies) that are perceived to be responsible for the deterioration of the economic situation in the homeland.

This allows us to put forward Negative Inevitable \# 9, as follows:

An introduction of new ICT as a tool of inter-economy competition will result in a compartmentalization of the social environment leading to the increased levels of hostility towards local and external groups perceived to be responsible for the deteriorating economic conditions of negatively impacted subgroups.

\subsection{Impact of Collaboration}

Finally, let us consider a case of an inter-economy collaboration- the case of two or more countries working on an ICT project. Unless the economies involved are fairly aligned, from a political, social, and cultural standpoint (e.g., Finland collaborating with Sweden), certain domination-based scenarios are bound to unfold. Culturally, a clash is inevitable and two simple outcomes of such clash are a disintegration of a project, or a submission of a weaker partner to the dominating counterpart. Politically, the impact will be felt by the "junior" member(s) of the project team because the power structure of the weaker member of a team will be under constant pressure of a "stronger" partner. Socially, the impact will be felt if the assignment of the roles and responsibilities of a weaker partner does not match the model of a more powerful entity. At this point we can state another Negative Inevitable, \#10, as

International collaborations on ICT will face the conflicts associated with and brought by the social, political, and cultural diversity of the collaborating members that will be resolved via the domination of more powerful member of the group.

\subsection{Investigating Negative Implications of ICT: What is the Plan?}

At this point it is time to start contemplating the means by which Negative Inevitables mentioned in this paper, as well as additional ones yet to be discovered and argued for, could be investigated.

We would like to propose a simple, two-step plan of action. First, researchers working in the area relevant to the subject matter must take into consideration, explicitly, negative implications of ICT. And this is not an easy thing to accomplish, for one would have to account for the negatives that take a part of ICT-based glory away. It will, indeed, require a paradigm shift away from the all too familiar "IT is good for development" attitude. Is a sharp knife good? Well, it depends... So, this "it depends" perspective must be embraced.

This allows us to formulate Research Suggestion \#1:

An investigation of positive socio-economic impacts of ICT should also consider, explicitly, collateral negative outcomes.

Second, investigators must consider the appropriate targets belonging to the different levels of inquiry. 
We consider three levels of granularity at which an investigation can be conducted- case studies, frameworks, and grand theories. In our view the three levels relate to each other as follows. Grand theories espouse relationships between general, context-independent constructs, frameworks operationalize the constructs in the context-specific manner, and case studies draw rich pictures of the context from "boots on the ground" perspective. Ideally, there will be a hierarchy and continuity of representation of the results and the data between the levels. Thus, findings of a case study should be possible to frame as a representation of a context-specific construct, and a context-specific construct should be possible to abstract and represent as a more general context-independent construct of a grand theory.

If one is to undertake a case study within the context of a single economy, then the local inflections must be identified. Meaning, it is fine and well that the farmers now have the cell phones to get the latest and the most accurate prices for their produce, but what happened to the dealers who used to direct the flow of the goods to the appropriate locations?

This allows us to formulate Research Suggestion \#2:

A case study dedicated to investigating socio-economic impacts of ICT should identify local, specific to the context of the case study, collateral negative outcomes.

In the case of an investigation relying on a framework, a researcher should be able to suggest, first, how a context-specific construct could be generalized to a context-independent one of a grand theory, and, second, how a context-specific construct may manifest itself in the "boots on the ground" setting. For example, if the results of a case study showed that an introduction of cell phones to a farming community resulted in elimination and substitution of local produce dealers, then what would the appropriate framework-level construct be?

We would like to formulate Research Suggestion \#3, as follows:

A framework-based research should incorporate within its model a context-specific construct representing collateral negative outcomes of ICT such that: (1) the construct could represent more specific local inflections of a case study-context, and, (2) the construct could be generalized to the level of theory.

Finally, if conducting a study backed by a theory, the investigator should attempt to include a general construct representing a collateral negative impact of ICT. Clearly, creating such construct will be driven more by philosophical consideration, then by practice. Nevertheless, the investigator must keep in mind that such a construct should be translatable to the level of a framework, and then to the level of a case study.

At this point we can formulate our Research Suggestion \#4:

A theory-based investigation should incorporate a context-independent construct representing collateral negative outcomes of ICT based on, and resulted from, the substitution and elimination nature of ICT.

We provide a brief illustration of the suggestions in Table 1. 
Table 1. Research Suggestions Taking into Consideration Negative Impacts of ICT

\begin{tabular}{|l|l|l|}
\hline Level & $\begin{array}{l}\text { Neoclassical Growth } \\
\text { Accounting }\end{array}$ & Modified Neoclassical Growth Accounting \\
\hline Theory & $\begin{array}{l}\text { EconOutput= (Labor, } \\
\text { Capital, TFP) }\end{array}$ & $\begin{array}{l}\text { EconOutput = (Labor, Capital, TFP, } \\
\text { - DisplacedLabor) }\end{array}$ \\
\hline Framework (IT_Labor, & $\begin{array}{l}\text { GDP=(IT_Labor, IT_Capital, TFP, } \\
\text { - Displaced_IT_Labor) }\end{array}$ \\
\hline Case study & $\begin{array}{l}\text { Cell phone usage by } \\
\text { farmers in Economy X } \\
\text { resulted in increasing level } \\
\text { of income due to the } \\
\text { improved access to a local } \\
\text { pricing system }\end{array}$ & $\begin{array}{l}\text { Cell phone usage by farmers in Economy X } \\
\text { resulted in increasing level of income of the } \\
\text { farmers due to the improved access to a local } \\
\text { pricing system, but it also resulted in elimination } \\
\text { and substitution of the services of local produce } \\
\text { brokers resulting in.... }\end{array}$ \\
\hline
\end{tabular}

Level-specific considerations for investigating negative impacts of ICT.

\section{Conclusion}

One of the most important issues that researchers and practitioners must address is that of a chosen granularity of a project. In the case of academics, for example, it concerns the level of investigation and, correspondingly, the level of research questions that are going to be stated. For all intents and purposes this deals with selecting along the "general-to-specific" (e.g., grand theory to case study) spectrum of an inquiry. If, let us say, a research question deals with the finding an impact of $\mathrm{X}$ on $\mathrm{Y}$ and the impact is found to be significant, then it is only so for the level of the context of the study. If an investigation is context-specific, then the findings also are. What was found positive for the wealthy may not be so for the poor (Harris, 2016).

Similarly, practitioners working in the area of ICT deal with projects introducing a change into a particular context, and the context could be very narrow (e.g., level of a department), or it could be very broad (e.g., level of economy). The chosen context carries a corresponding level of scrutiny regarding the success of the project. So, if an implementation of a new software for HR Department was a successful one, then the designation of a "successful project" was based on the stated in advance criteria (e.g., let us say, satisfaction of user requirements) specific to the context of the project. The success of the project at the level of a department may bring negative consequences along the "general-to-specific" spectrum- it may negatively impact an employee of the HR Department, and it could bring some negatives at the level of the firm that houses the department.

There is a general similarity between researchers and practitioners working in the area of ICT, and this similarity is in terms of the impact of ICT. Most of the time, the investigators are searching for a positive impact of ICT, and, all the time practitioners have in mind obtaining a positive impact of ICT. The problem is, of course, is that of context. And the question is, at what level? 
Any introduction of change results in an impact. And it is impossible to have a positive impact without some negative aspects manifesting themselves here and there. If we operate in a single context, which is akin to having a tunnel vision, then we may not see the negatives lurking "here and there." Interestingly, despite the fact that the tools allowing for a multi-level consideration of the context were available to researchers and practitioners for quite some time (Jackson, 1982, Arnold \& Wade, 2015), we don't see their widespread application.

\section{References}

Arnold, R., \& Wade, J. (2015). A definition of systems thinking: a systems approach, Procedia Computer Science, 44, 669-678. https://doi.org/10.1016/j.procs.2015.03.050

Bosamia, M. P. (2013). Positive and Negative Impacts of Information and Communication Technology in our Everyday Life. In proceedings of International Conference on Disciplinary and Interdisciplinary Approaches to Knowledge Creation in Higher Education: Canada \& India (GENESIS 2013).

Harris, R. (2016). How ICT4D Research Fails the Poor. Information Technology for Development, 22(1), 177-192. https://doi.org/10.1080/02681102.2015.1018115

Jackson, M. (1982). The Nature of "Soft" System Thinking: The Work of Churchman, Ackoff, and Checkland. Journal of Applied Systems Analysis, 9, 17-29.

Tarafdar, M., DArcy, J., Turel, O., \& Gupta, A. (2015). The dark side of information technology. MIT Sloan Management Review, 56(2), 61-70.

Tarafdar, M., Gupta, A., \& Turel, O. (2013). The dark side of information technology use. Information Systems Journal, 23(3), 269-275. https://doi.org/10.1111/isj.12015

\section{Copyright Disclaimer}

Copyright for this article is retained by the author(s), with first publication rights granted to the journal.

This is an open-access article distributed under the terms and conditions of the Creative Commons Attribution license (http://creativecommons.org/licenses/by/4.0/). 